\title{
Statistical study of the night-time F-layer dynamics at the magnetic equator in West Africa during the solar minimum period 1995-1997
}

\author{
K. S. Tanoh ${ }^{1}$, B. J.-P. Adohi ${ }^{1}$, I. S. Coulibaly ${ }^{1}$, C. Amory-Mazaudier ${ }^{2,3}$, A. T. Kobea ${ }^{1}$, and P. Assamoi ${ }^{1}$ \\ ${ }^{1}$ Laboratoire de Physique de l'Atmosphère, Université Félix Houphouët-Boigny de Cocody, \\ 22 B.P. 582 Abidjan 22, Côte-d'Ivoire \\ ${ }^{2}$ Sorbonne Paris, UPMC Univ. Paris VI, LPP, 4 place Jussieu, 75252 Paris, France \\ ${ }^{3}$ T-ICT4D, International Centre for Theoretical Physics, Strada Costera 11, 34151 Trieste, Italy \\ Correspondence to: B. J.-P. Adohi (pierreadohi@yahoo.fr)
}

Received: 6 June 2014 - Revised: 15 December 2014 - Accepted: 17 December 2014 - Published: 30 January 2015

\begin{abstract}
In this paper, we report on the night-time equatorial F-layer height behaviour at Korhogo $\left(9.2^{\circ} \mathrm{N}, 5^{\circ} \mathrm{W}\right.$; $2.4^{\circ} \mathrm{S}$ dip lat), Ivory Coast, in the West African sector during the solar minimum period 1995-1997. The data were collected from quarter-hourly ionograms of an Ionospheric Prediction Service (IPS) 42-type vertical sounder. The main focus of this work was to study the seasonal changes in the F-layer height and to clarify the equinox transition process recently evidenced at Korhogo during 1995, the year of declining solar flux activity. The F-layer height was found to vary strongly with time, with up to three main phases. The night-to-night variability of these morphological phases was then analysed. The early post-sunset slow rise, commonly associated with rapid chemical recombination processes in the bottom part of the F layer, remained featureless and was observed regardless of the date. By contrast, the following event, either presented like the post-sunset height peak associated with the evening $\boldsymbol{E} \times \boldsymbol{B}$ drift, or was delayed to the midnight sector, thus involving another mechanism. The statistical analysis of the occurrence of these events throughout the solar minimum period 1995-1997 revealed two main F-layer height patterns, each characteristic of a specific season. The one with the post-sunset height peak was associated with the northern winter period, whereas the other, with the midnight height peak, characterized the northern summer period. The transition process from one pattern to the other took place during the equinox periods and was found to last only a few weeks. We discuss these results in the light of earlier works.
\end{abstract}

Keywords. Ionosphere (equatorial ionosphere; ionosphereatmosphere interactions; ionospheric irregularities)

\section{Introduction}

The equatorial F-layer dynamics have been the subject of several theoretical and experimental works in the last 40 years, mainly through a large number of plasma-drift and spread-F investigations. Some of the initial works, conducted using incoherent scatter radar at Jicamarca in Peru, provided major information on the seasonal variations in the F-region vertical and zonal drifts (Fejer et al., 1979, 1989). As an example, the evening prereversal enhancement of the vertical drift velocity takes place whatever the season in maximum solar activity conditions, but its amplitude is smallest from May to August. In minimum solar activity conditions, the enhancement takes place only during the periods from February to May and from August to November. Later, night-time zonal drifts in the $\mathrm{F}$ region were derived from very highfrequency (VHF) backscatter radar observations at Trivandrum. The altitudinal variations in the zonal drifts revealed large vertical shears (Krishna Murthy and Subbarao, 1994). Ionosonde observations have also been used to infer evening and night-time equatorial F-region vertical drifts (Batista et al., 1986) and to study the effects of both meridional neutral winds and F-layer height on the onset and the growth of equatorial spread-F (ESF) events at Fortaleza in Brazil (Sastri et al., 1997). Several theoretical predictions established the basic features of these plasma drifts and supported the experimental findings (Rishbeth, 1971; Eccles, 1998). Computational models also reproduced the observations (Heelis et al., 1974; Scherliess and Fejer, 1999). It is actually known that, across the sunset period, the F-region dynamo process creates a vertical polarization electric field $(\boldsymbol{E})$, downward at 
middle altitudes and upward at low altitudes in the $\mathrm{F}$ region, which, in combination with the magnetic field $(\boldsymbol{B})$, produces, respectively, the eastward and the westward $\boldsymbol{E} \times \boldsymbol{B}$ drifts evidenced in the experiments. In addition, the daytime eastward electric field is enhanced and produces a peak in the upward $\boldsymbol{E} \times \boldsymbol{B}$ drift before the reversal to the night-time downward $\boldsymbol{E} \times \boldsymbol{B}$ drift (Farley et al., 1986). When this upward drift is combined with the eastward and the westward drifts, it comprises the so-called "evening vortex" (Heelis, 2004). The evening vortex has been experimentally observed with the aid of incoherent scatter radar at Jicamarca, in a minimum solar activity period, and found centred at about $300 \mathrm{~km}$ altitude at 20:00 LT (Kudeki and Bhattacharyya, 1999).

Similarly, the upward vertical $\boldsymbol{E} \times \boldsymbol{B}$ drift can be observed via the motion of the $\mathrm{F}$ layer in ionograms. Its pattern in a 2-D height-time coordinates system is a single height peak near 19:00 LT (the amplitude of which is about $300 \mathrm{~km}$ ) as models showed (Maruyama et al., 2002).

The $\boldsymbol{E} \times \boldsymbol{B}$ drift is investigated in several works. The diurnal pattern observed by the Communication/Navigation Outage Forecast System (C/NOFS) satellite during solar minimum (Pfaff et al., 2010) showed downward drifts in the afternoon and upward drifts in the midnight sector at some equatorial locations, which contrasts with the usual observations of upward drifts during daytime and downward drifts at night (Balan et al., 2012). When investigating the effects of magnetic storm on the F-layer height in the Indian sector, the night-time pattern observed by Sastri et al. (2002) during the reference quiet day at Trivandrum and Kodaikanal close to the magnetic equator first showed an evening uprising and then remained steady at about $320 \mathrm{~km}$ until 03:15 LT before descending. This long-lasting uplift also differs from the pattern that is usually observed. Therefore, it would be useful to issue repeated observations for further comparisons and the improvement of simulation models of the F-layer height variations.

In addition to the $\boldsymbol{E} \times \boldsymbol{B}$ drift, two other processes are generally involved in the night-time F-layer height variations. The one, the ion-electron chemical recombination process is dominant at the bottom of the F layer in the early sunset when photoionization ceases, resulting in a rise of the bottom layer height (Maruyama, 1996). The other is the meridional neutral wind, which has the effect of pushing up (down) the F-region plasma according to the latitude of the station and the direction of the wind (Chan and Walker, 1984; Mueller-Wodarg, 2001).

Most of the investigations of the F-layer dynamics have not concerned African regions. Therefore, data from this sector are comparatively few. Farges and Vila (2003) investigated the occurrence of ESF in relation to the night-time F-layer height variations based on quarter-hourly ionograms at Ouagadougou $\left(12.4^{\circ} \mathrm{N}, 1.4^{\circ} \mathrm{W} ; 1.5^{\circ} \mathrm{N}\right.$ dip lat), BurkinaFaso, and Dakar $\left(14.8^{\circ} \mathrm{N}, 17.4^{\circ} \mathrm{W} ; 5^{\circ} \mathrm{N}\right.$ dip lat), Sénégal, during the period from December 1994 to November 1995. The ESF evolution revealed seasonal, latitudinal and mag- netic activity dependences and the temporal evolution of the F-layer height differed slightly from one site to the other. However, their investigation left undone the study of the night-to-night variability of the F-layer height pattern. Recently a study has been carried out on this subject using ionograms data at Korhogo $\left(9.2^{\circ} \mathrm{N}, 5^{\circ} \mathrm{W} ; 2.4^{\circ} \mathrm{S}\right.$ dip lat), Ivory Coast, in the West African sector (Adohi et al., 2008). This study revealed an additional uplift around midnight in addition to the evening uplift due to the prereversal $\boldsymbol{E} \times \boldsymbol{B}$ drift enhancement. However, the study was restricted to the short period of March-April 1995 and could not provide information on the seasonal behaviour of this additional uplift.

The purpose of the current paper is to extend this work over the solar minimum period of 1995-1997 and, particularly, to analyse the seasonal variability of the F-layer height at Korhogo.

In Sect. 2, we will present the data sets and the data processing. Section 3 will be devoted to the experimental results. First, we will successively present the main night-time F-layer height patterns, their night-to-night changes and their seasonal trends over the year 1995. Then we will extend the study of the seasonal behaviour over the whole solar minimum period of 1995-1997. In Sect. 4, we will discuss our results in the light of actual data concerning ionosphere dynamics. Finally, in Sect. 5, we will draw our conclusions based on these results.

\section{Data sets and data processing}

The data acquisition and processing have been described in detail in previous papers (Farges and Vila, 2003; Adohi et al., 2008). However, we will summarize the main points. The device set up at Korhogo is a vertical-sounding IPS 42-type transmitter-receiver with an antenna $80 \mathrm{~m}$ wide and $25 \mathrm{~m}$ high. The transmitter pulse has a $2 \mu$ s rise time and is $10 \mu \mathrm{s}$ wide. The peak power transmitted is $5 \mathrm{~kW}$. The ionosonde operates in the high frequency (HF) range $[1-22 \mathrm{MHz}]$ and provides the plot of the virtual height as a function of frequency every $15 \mathrm{~min}$.

Two height parameters are commonly determined from such a plot. The bottom level altitude $h^{\prime} \mathrm{F}$ is extrapolated from the low-frequency asymptotic value of the virtual height. The upper level altitude $h p \mathrm{~F} 2$ is read on the ordinary trace and is taken as the virtual height for the plasma frequency 0.832 $f o \mathrm{~F} 2, f o \mathrm{~F} 2$ being the critical frequency. The parameters $h^{\prime} \mathrm{F}$ and $h p \mathrm{~F} 2$ are determined every $15 \mathrm{~min}$. This allows us to collect 48 pairs of data $\left(h^{\prime} \mathrm{F}, h p \mathrm{~F} 2\right)$ every night from 18:00 to 06:00 LT. The plot of these parameters as a function of time delineates the F-layer semi-thickness and allows studying night-time F-layer dynamics (Farges and Vila, 2003). However, the variations in $h^{\prime} \mathrm{F}$ are usually taken as a good estimate of the vertical motion of the $\mathrm{F}$ layer during night-time and when $h^{\prime} \mathrm{F}$ is high enough for the recombination effect to be ignored (Chandra and Rastogi, 1972a; Saito and Maruyama, 
Table 1. Nights with no data in 1995 and 1997

\begin{tabular}{lrr}
\hline \multicolumn{3}{c}{ Nights with no data } \\
\hline Months & 1995 & 1997 \\
\hline April & $9-10$ & \\
June & $12-13$ & $1-2$ \\
June & & $2-3$ \\
July & $8-9$ & \\
July & $29-30$ & \\
August & $19-20$ & \\
\hline
\end{tabular}

2006). Therefore, the plot of this parameter only, as a function of time, will be used in this paper.

The variations in the F-layer height were studied over the period 1995-1997 around the solar minimum. The ionosonde operated continuously during the years 1995 and 1997, except during five nights for 1995 and two for 1997 (Table 1). For these nights no data were available. From the data collected during the other nights, we plotted a series of 359 height-time patterns for 1995 and 362 for 1997 that allowed studying the night-to-night variability of the F-layer height over these years. Gaps due to the missing nights did exist in our series of patterns but could not significantly influence the analysis owing to their low frequency ( 5 nights out of 364 for 1995 and 2 out of 364 for 1997) and their erratic distribution throughout the 2 years (Table 1). For the year 1996, no data were available during the 2-month period August-September due the ionosonde breaking. Hence, the variations in the Flayer height were studied over the periods January-July and October-December and were compared to those of 1995 and 1997.

Both magnetically quiet and disturbed nights were studied in this work. The well-known difficulty is that, during magnetically disturbed periods, the geomagnetic activity may influence the F-layer height significantly, making the interpretation of the night-to-night changes difficult. In order to determine and characterize the level of geomagnetic activity, two indices are most often used, namely, the Kp (Ap) and $\mathrm{Km}(\mathrm{Am})$ indices (Zerbo et al., 2013). Both describe the geomagnetic activity on the planetary scale. Likewise, the Kp and Ap indices as well the $\mathrm{Km}$ and Am ones provide the same measure of geomagnetic activity on two different scales (Kp and $\mathrm{Km}$ are given on a scale from 0 to 9 while Ap and Am are expressed in $\mathrm{nT}$ ). The main difference between the two sets of indices lies in the distribution of the observatories from which they are computed. The $\mathrm{Km}(\mathrm{Am})$ indices are determined from 12 observatories in the Northern Hemisphere and 9 in the Southern Hemisphere whereas the Kp (Ap) indices are computed from 12 observatories in the Northern Hemisphere and only 2 in the Southern Hemisphere. Similarly, the longitudinal coverage of these observatories is better in the case of the $\mathrm{Km}(\mathrm{Am})$ indices than in that of the $\mathrm{Kp}(\mathrm{Ap})$ ones. Menvielle and Berthelier (1991) reviewed and discussed the derivation of the K-derived planetary indices. They pointed out that it is better to use the Am or $\mathrm{Km}$ indices as they give a better description of the geomagnetic activity than the Ap or $\mathrm{Kp}$ indices. Therefore in this paper, in order to characterize the magnetic activity, we will use the mean daily index, Am.

\section{Results and analysis}

\subsection{Time variations in the F-layer height}

Figure 1 shows typical examples of the night-time variation of $h^{\prime} \mathrm{F}$ observed in magnetically quiet conditions $(\mathrm{Am} \leq 20)$. The temporal variation of $h^{\prime} \mathrm{F}$ in Fig. 1a (10-11 January 1995; $A m=14$ ) exhibits a single narrow peak, and the whole period can be divided into three phases - I, II, and III - as shown by the vertical dashed lines. In phase I, the layer moves up very slowly, from $250 \mathrm{~km}$ at 18:00 LT to $260 \mathrm{~km}$ at about 18:45 LT, with an average apparent velocity of about $4 \mathrm{~m} \mathrm{~s}^{-1}$. This motion is very often attributed to the rapid chemical recombination process that is predominant in the early sunset period (Maruyama et al., 2002). In phase II, the ascendant motion is significantly accelerated at 18:45 LT (Fig. 1a), clearly indicating a change in the mechanism underlying the layer motion, and the layer height reaches a maximum of about $338 \mathrm{~km}$ at 20:15 LT and then descends to an altitude of about $230 \mathrm{~km}$ at 22:15 LT. The average apparent velocity of $14 \mathrm{~m} \mathrm{~s}^{-1}$ during the rise is more than 3 times higher than that in phase I $\left(4 \mathrm{~m} \mathrm{~s}^{-1}\right)$. A maximum vertical displacement of about $88 \mathrm{~km}$ is comparable to those found in other works (Batista et al., 1986). The peak of phase II is well known and is generally interpreted as a signature of the evening $\boldsymbol{E} \times \boldsymbol{B}$ drift enhancement (Fejer and Scherliess, 1999). Finally, during the rest of the night in phase III, the layer remains steady at an altitude of about $215 \mathrm{~km}$. This phase is often associated with chemical processes that control the layer altitude in the bottom part of the F layer (Maruyama et al., 2002). In the following, the temporal variation in Fig. 1a will be taken as a reference for further comparisons as it is observed more frequently. The temporal variation of $h^{\prime} \mathrm{F}$ (Fig. 1b) on the quiet night of 12-13 May 1995 $(A m=12)$ also exhibits a slowly ascendant motion in phase I as in Fig. 1a. By contrast, the rise and fall motion expected after 19:00 LT in phase II is not observed and the layer remains nearly steady at an altitude of $260 \mathrm{~km}$ until 22:15 LT. In addition, phase III is no longer featureless but exhibits a new rise and fall motion that starts at 22:15 LT, with a delay time of $3 \mathrm{~h} 30 \mathrm{~min}$ as compared to that of phase II in Fig. 1a. As a consequence, the height peak is delayed until 00:45 LT (Fig. 1b). We have to specify here that the entire temporal evolution is sometime missing if the layer density becomes small and the signal is correspondingly degraded. Such behaviour is shown in the examples of Fig. 2 in which the layer disappeared sooner than in Fig. 1b. On the quiet night of 13 14 May 1995 (Fig. 2a), the layer disappeared near $340 \mathrm{~km}$ 


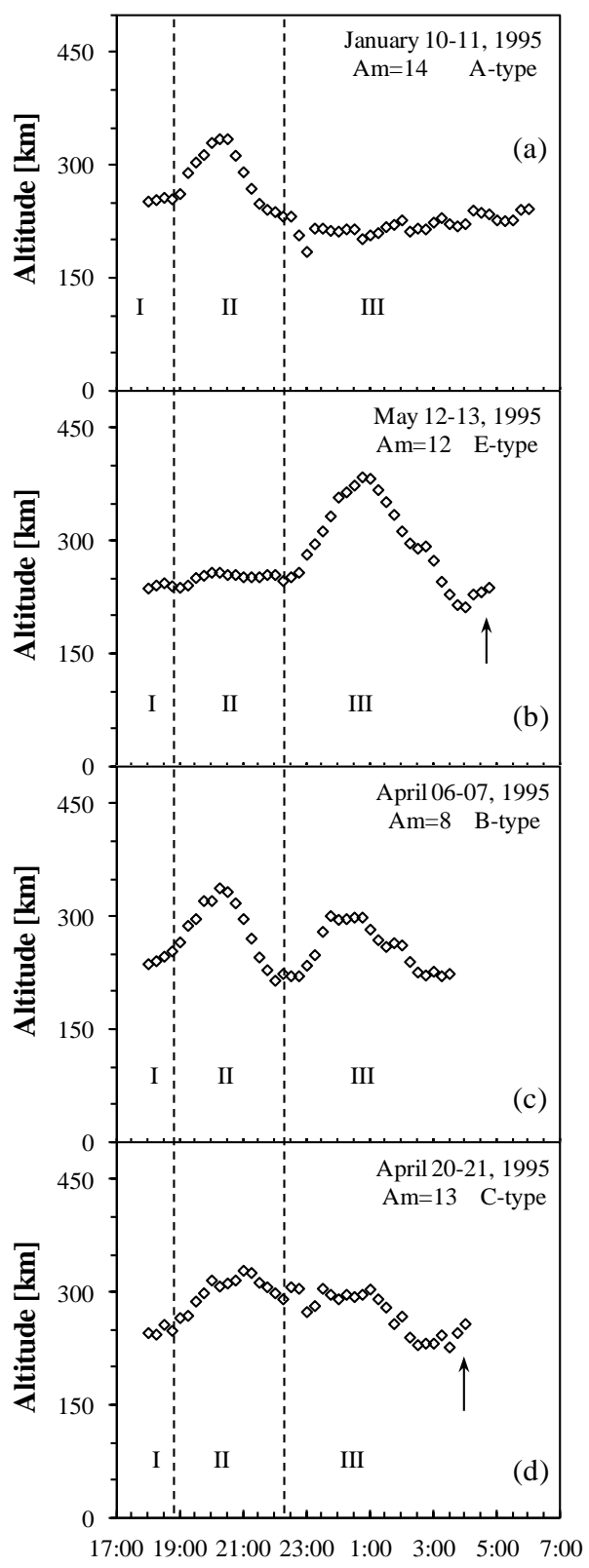

Local Time [h]

Figure 1. Typical F-layer height variations as a function of LT time observed throughout the whole solar minimum period 1995-1997 at Korhogo. The vertical dashed lines divide the night-time patterns into three main parts (I, II, III), each associated with a specific mechanism: (a) the A-type pattern characterized by a single height peak in phase II associated with the well-known evening upward $\boldsymbol{E} \times \boldsymbol{B}$ drift; (b) the E-type pattern characterized by a single height peak in phase III in the midnight sector; (c) the B-type pattern regrouping the A- and E-type patterns; (d) the C-type pattern with a single height peak characterized by a steady state. The upward arrows in phase III of panels (b) and (d) indicate another elevation motion of the F layer probably due to pre-sunrise phenomena.
Table 2. Statistics of the observations over the year 1995 .

\begin{tabular}{lrrrrr}
\hline Types of pattern & (A) & (B) & (C) & $(\mathrm{E})$ & $(\mathrm{O})$ \\
Number of observations & 173 & 63 & 9 & 106 & 8 \\
Occurrence (\%) & 48.2 & 17.5 & 2.5 & 29.5 & 2.2 \\
\hline
\end{tabular}

during the descent at about 02:30 LT, whereas, on the night of 15-16 May 1995 (Fig. 2b), it could no longer be detected after 02:00 LT during the upward motion. For the current case in Fig. 1b, another rising motion (indicated by the upward arrow in phase III) is initiated at 04:00 LT, probably due to pre-sunrise phenomena (Farges and Vila, 2003). Figure 1c depicts the third example of $h^{\prime} \mathrm{F}$ temporal variation on the quiet night of 6-7 April 1995 (Am = 8), which exhibits both evening and midnight uplifts. The slow rise in phase I, the same as Fig. 1a, is clearly exhibited until 18:45 LT (Fig. 1c). This is successively followed by the evening uplift in phase II (the same as Fig. 1a) and the midnight uplift in phase III (the same as Fig. 1b). However, the peak altitude of phase III in Fig. 1c $(\sim 310 \mathrm{~km})$ is lower than that in Fig. 1b $(\sim 390 \mathrm{~km})$, while the time of the peak in Fig. 1c (00:15 LT) is $30 \mathrm{~min}$ earlier than that in Fig. 1b (00:45 LT). We consider another example on the quiet night of 20-21 April 1995 (Am =13) in Fig. 1d. As in Fig. 1a, the post-sunset rising motion of phase I is followed, near 19:00 LT, by a rapid layer uprising until 20:30 LT, reminiscent of the prereversal enhanced electric field effect. However, the maximum altitude of about $310 \mathrm{~km}$ is slightly lower than that in Fig. 1a ( $338 \mathrm{~km})$, and the layer remains practically steady at that altitude for about $4 \mathrm{~h} 30 \mathrm{~min}$ (Fig. 1d). The descent motion starts at 01:00 LT and takes the layer down to $230 \mathrm{~km}$ at 03:00 LT. Then, the pre-sunrise ascendant motion is initiated as in Fig. 1b. The major difference in the layer height pattern between Fig. 1d and $\mathrm{a}$ is the presence of the steady state in Fig. 1d. Most of the time in our experiments, it lasted for about $5 \mathrm{~h}$. Unlike the examples shown in Fig. 1, there were a few nights on which $h^{\prime} \mathrm{F}$ did not change significantly throughout the night. Such an example is shown in Fig. 3. In the rest of this paper, the temporal variation of $h^{\prime} \mathrm{F}$ in Fig. 1 will be referred to as the A type in the case of evening uplift (Fig. 1a), the E type in the case of midnight uplift (Fig. 1b), the B type when both the evening and midnight uplifts occur (Fig. 1c) and the $\mathrm{C}$ type when there is a single broad uplift showing a steady state (Fig. 1d). The temporal variation without significant $h^{\prime} \mathrm{F}$ changes throughout the night will be referred to as O type (Fig. 3). Table 2 shows the occurrence probability of each type of $h^{\prime} \mathrm{F}$ variation for 1995. The A- and E-type patterns dominate with, respectively, 173 and 106 observations out of 359 , i.e. $48.2 \%$ of our series for the A type and $29.5 \%$ for the $\mathrm{E}$ type. The B-type pattern is observed fairly often ( $17.5 \%$ of the series), and the $\mathrm{C}$ and $\mathrm{O}$ types are rare, with only 9 and 8 observations throughout the year, respectively. 


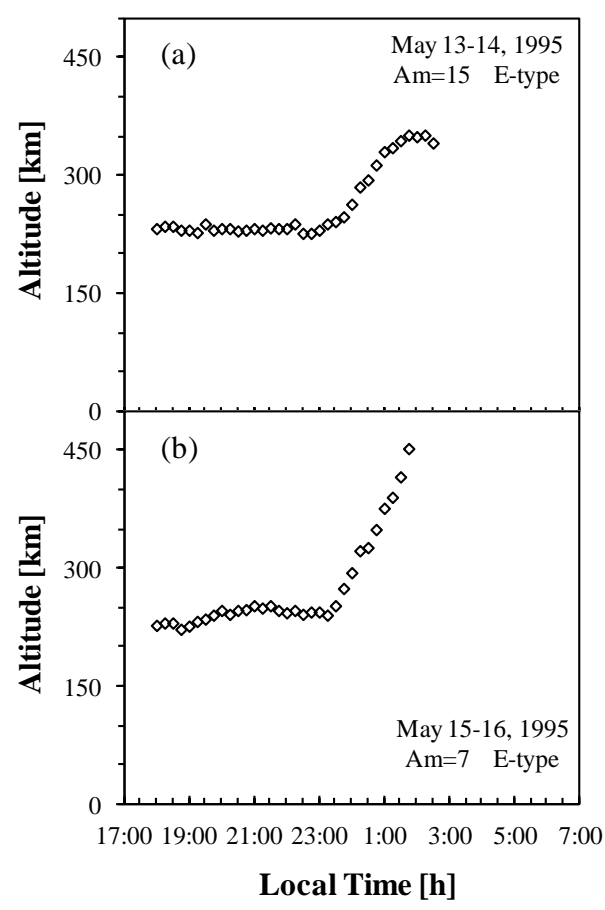

Figure 2. F-layer height variations as a function of LT time showing non-fully developed E-type pattern. In (a) the layer has disappeared early after the peak; in (b) the layer has disappeared before the peak is reached.

\subsection{Night-to-night variations in $h^{\prime} \mathrm{F}$ over the year 1995}

\subsubsection{Seasonal occurrence of the F-layer patterns}

In this section, we study the occurrence of each type of $h^{\prime} \mathrm{F}$ variation pattern determined in the previous section from one night to the next. For this purpose, we divided the whole year into 52 intervals (numbered from 1 to 52), each consisting of 7 nights and, therefore, extending over 1 week. In each interval, we counted the number of observations of each type of pattern; then we represented the histogram of the observations as a function of the number of the intervals. We should note here that, in such a study, only the shape of the temporal variation is important, not the amplitude of the height peaks, so that both magnetically quiet and disturbed nights were used. Similarly, the number of intervals, 52, was found suitable both for clarity in the presentation of the histograms and to avoid information losses in their interpretation. Figure 4 shows such representations. In each panel, the ordinate is the occurrence number of the type of variation, while the abscissa is the week of the year. An interesting feature that emerges from these figures is that, when every type of pattern begins, it lasts for a particular period of the year that can be longer or shorter before it vanishes, revealing a seasonal behaviour of the mechanism that controls the layer height variations.

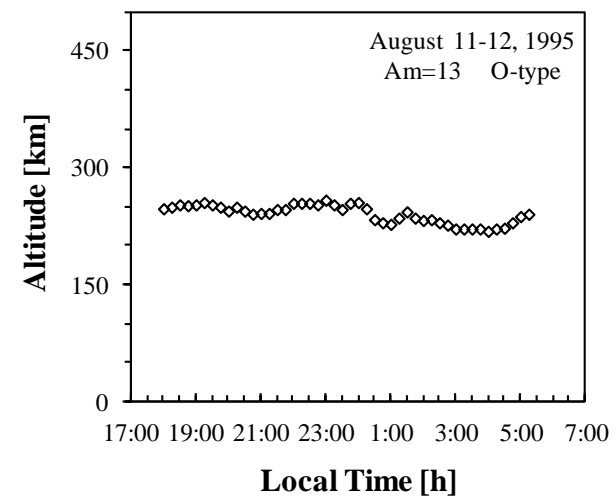

Figure 3. F-layer height variations as a function of LT time with no significant motion. This pattern is termed O-type pattern.

In Fig. 4a, the A-type pattern clearly occurs in week 1 to week 13 and then from week 37 to week 52 . In other words, the A-type pattern occurs over two periods of 3 months: from January to nearly the end of March and then from October to the end of December. Throughout these periods, the A-type pattern is continuously observed (up to 7 nights every week), except in the periods around the weeks 5 and 49, in which as few as 4 appearances are registered (Fig. $4 a$ ). Therefore, we consider the 6-month period from October to near the end of March as the season of the A-type pattern.

Figure $4 \mathrm{~b}$ depicts the histogram of the observations of the E-type pattern. It is observed that this type of height variation starts in week 16, with only one appearance, then gets more and more frequent and, finally, is the only pattern observed over the period extending from week 18 to week 33, with an occurrence frequency of 7 nights every week except in weeks 24, 27 and 30, in which 6 observations are registered, the missing night being due to the ionosonde breaking (Table 1 provides the list of the nights with no data). Beyond week 33, the E-type pattern ceases progressively and becomes erratic with only 2 occurrences in week 36 (Fig. 4b). This indicates that, the interval of weeks 18-33, namely, the period from May to mid-August, is the season of the E-type pattern.

Considering now the B- and C-type patterns, it was observed experimentally that (1) both occur nearly in the same period of the year and last only a few weeks and (2) the peak of the midnight uplift shifts in time from one night to the next (Adohi et al., 2008). These results suggest that the C-type pattern may be regarded, at first sight, as a B-type pattern with a short time difference between the two uplifts. Therefore, for the purpose of this analysis, the C-type pattern was considered to be a special case of the $\mathrm{B}$ type. The resulting histogram for the combination of the B- and C-type patterns (B/C type) is shown in Fig. 4c. It is interesting to note that the duration of the $\mathrm{B} / \mathrm{C}$-type pattern is short and that the $\mathrm{B} / \mathrm{C}$ type pattern arises four times over the year, namely in weeks $3-7,13-20,34-37$ and $47-52$. We note also that, in weeks 13-20, the B/C-type pattern starts erratically with only two 

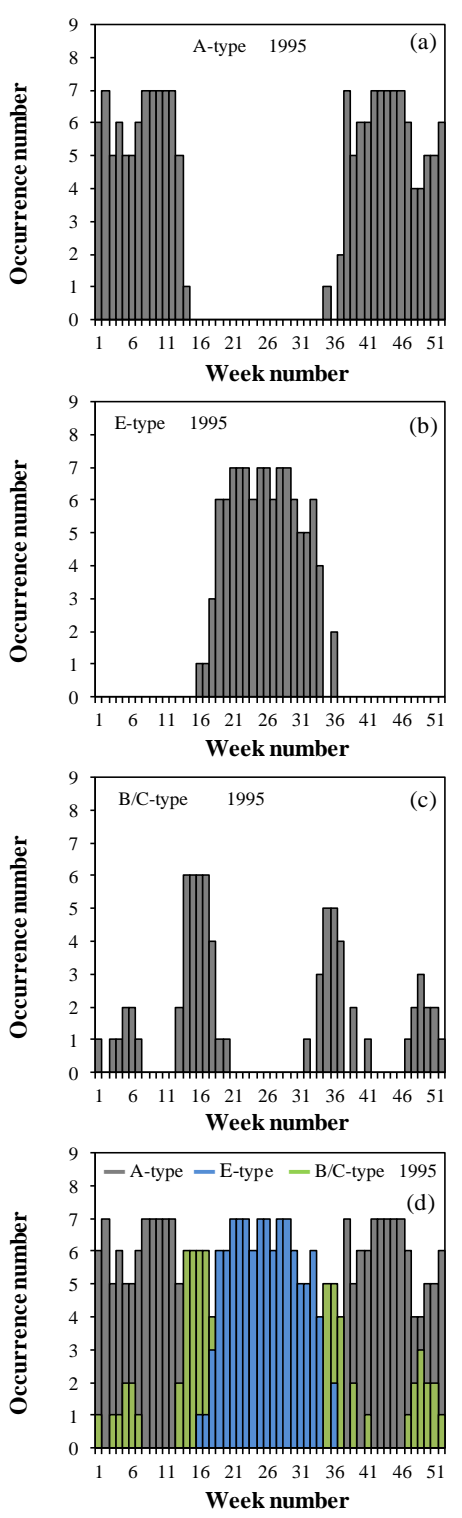

Figure 4. Histograms of the occurrences of the F-layer pattern types over the year 1995. The ordinate axis in each panel displays the occurrence number of the pattern type, and the abscissa shows the nights divided into weeks. Seasonal behaviours are exhibited. In (a) the A-type pattern occurs during weeks 1-13 and 37-52, namely from October to the end of March including the northern winter period; in (b) the E-type pattern occurs during weeks 18-33, namely from May to mid-August including the northern summer period; in (c) the B- and C-type patterns (together as an identical F-layer pattern termed B/C-type) occur mainly during weeks 14-18 and 34-37, namely during the equinox periods, and this is, therefore, considered the main season of the B/C-type pattern. Also in (c) the B/Ctype pattern occurs erratically during weeks 3-7 and 47-52, namely from mid-January to mid-February and from mid-November to the end of December. These periods are considered as secondary seasons of the B/C-type pattern; in (d) the A-, E- and B/C-type patterns are shown together. observations, then dominates over 5 weeks within the interval of weeks 14-18 with up to six observations out of seven possible ones, and ceases progressively. Similar behaviour is observed in weeks 34-37, with up to five observations out of seven possible ones during the 3 -week interval 35-37. Therefore, we consider weeks $14-18$ and 34-37, namely, the periods from the last week of March to the end of April and from mid-August to mid-September, as the main seasons of the B/C-type pattern. The observations of the B/C-type pattern are comparatively few in weeks $3-7$ and $47-52$, i.e. less than three every week, but their evolution on the successive nights is similar. That is, the B/C-type pattern starts erratically with only one appearance per week, then gradually becomes frequent, with a maximum occurrence frequency of three per week, and progressively disappears (Fig. 4c). This evolution is reminiscent of random phenomena and suggests that the mechanism that controls the midnight uplift of the B/C-type pattern may take place randomly every night in weeks 3-7 and $47-52$, namely, in the periods from mid-January to midFebruary and from mid-November to nearly the end of December. Accordingly, we consider these periods as the secondary seasons of the B/C-type pattern.

Concerning the O-type pattern, a similar statistical study was not possible due to its low occurrence percentage as shown in Table 2. However, we can show that the O-type pattern is erratically distributed throughout the year with, as an example, two observations in week 31 and one in week 32; this explains the gap observed in weeks $31-32$ in Fig. 4b.

\subsubsection{The equinox transitions}

When we combine the occurrence statistic in Table 2 and the histograms of all the types of pattern in Fig. 4d, we can clearly distinguish two main variations in $h^{\prime} \mathrm{F}$ throughout the year, each associated with a geophysical season. One is the A-type pattern because (1) it is observed more often, with a yearly occurrence probability of up to $48.2 \%$ (Table 2), and (2) it is associated with a more extended season, from October to almost the end of March, including the northern winter period (Fig. 4d). The other, the E-type pattern with a nearly $30 \%$ yearly occurrence probability (Table 2 ), probably characterizes the northern summer period, from May to August (Fig. 4d). The transition from the regime with the A-type pattern (resp. the E-type pattern) to that with the E-type one (resp. the A-type one) likely occurs within the short intermediate period from the end of March to the end of April (resp. mid-August to mid-September), around the spring equinox (resp. the autumn equinox). In that transition period, both types of uplift coexist on the same nights (B/C type), as observed in Fig. 1c, indicating that the mechanisms that govern the associated motions are both involved but act separately, their peak instants being distinct. 


\subsection{Seasonal variations in $h^{\prime} \mathbf{F}$ around the solar minimum period 1996-1997}

In Figs. 5 and 6, we show the histograms of the observations of the $h^{\prime} \mathrm{F}$ variation patterns for 1996 and 1997, respectively. There are similar features to those in 1995 (Fig. 4), although a large data gap exists within the week interval 31-39 (Fig. 5d) due to the ionosonde breaking in 1996. The A and E types are observed around the northern winter and summer periods, respectively, and the $\mathrm{B} / \mathrm{C}$ type mainly around the equinoxes (Figs. 5 and 6). The secondary seasons of the B/C-type pattern are also shown, mainly in the periods January-February 1996 (Fig. 5c and d), i.e. in weeks 1-7, and November-December 1997 (Fig. 6c and d), i.e. in weeks 44-50. In November-December 1996, the season of the B/C type is not clearly delimited due to two erratic appearances in weeks 43 and 46 (Fig. 5c and d). Similarly, in JanuaryFebruary 1997, the data show some dispersion and the most probable weeks for B/C-type occurrence are not clearly evidenced (Fig. $6 \mathrm{c}$ and d).

\subsection{Characteristics of the A-, E- and B-type patterns}

In this section, we study the night-to-night variations in the characteristic parameters of the height peaks in the A-, Eand B-type patterns over the solar minimum period 19951997. The investigations were carried out for magnetically quiet nights $(\mathrm{Am} \leq 20)$. The main handicap in such a study is that the size of the data sample depends on the number and the duration of the magnetically disturbed periods and the lower that size, the higher the number of the disturbed periods and the longer their duration. In our experiment, numerous periods of magnetic storms were identified. The second hindrance is that, in the case of the E-type patterns, the layer density is sometime degraded before the uprising motion reaches its maximum. When this happens, only the time at the start of the elevation can be measured, not the parameters at the maximum. The third hindrance is that, in the case of the B-type pattern, the period of the observations is short (a few weeks of equinox) and the number of observations is correspondingly reduced. Owing to the above difficulties, samples of 120 patterns of A- and E-type variations and 82 patterns of B-type variation were available on magnetically quiet nights. Table 3 lists the selected nights. One notices that the number of nights used for the study varies according to the months and the years as the number and the duration of the magnetically disturbed periods vary. However, the distribution of these nights covers the entire period of the solar minimum so that the characteristic parameters of the $F$ layer were taken as representative of that period. Figure $7 \mathrm{a}, \mathrm{b}$ and $\mathrm{c}$ depict the temporal variations in $h^{\prime} \mathrm{F}$ in the A-, E- and B-type patterns, respectively.

It is interesting to note in Fig. 7a that there is no strong dispersion of the experimental data. This clearly indicates that (1) the A-type pattern is stable and its characteristic parame-
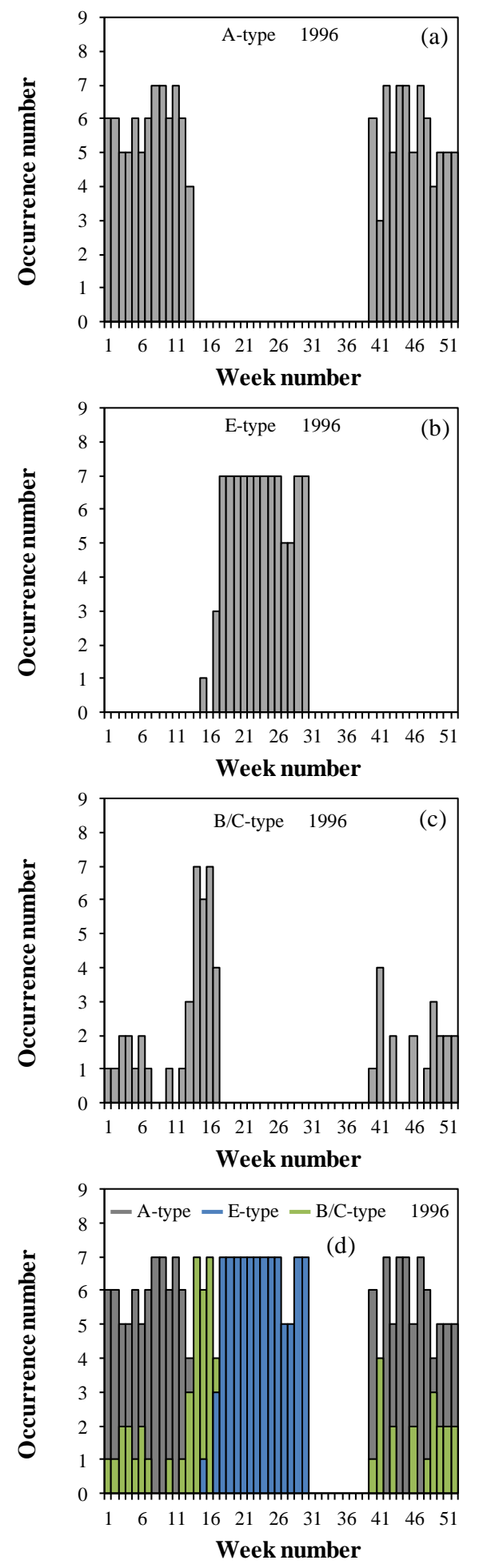

Figure 5. Same as Fig. 4 but for 1996, with clear seasonal behaviours of the F-layer patterns except with regard to the secondary season of the $\mathrm{B} / \mathrm{C}$ type during the period of November-December in (c). In (d), the large gap within weeks 31-39 is due to the ionosonde breaking. 

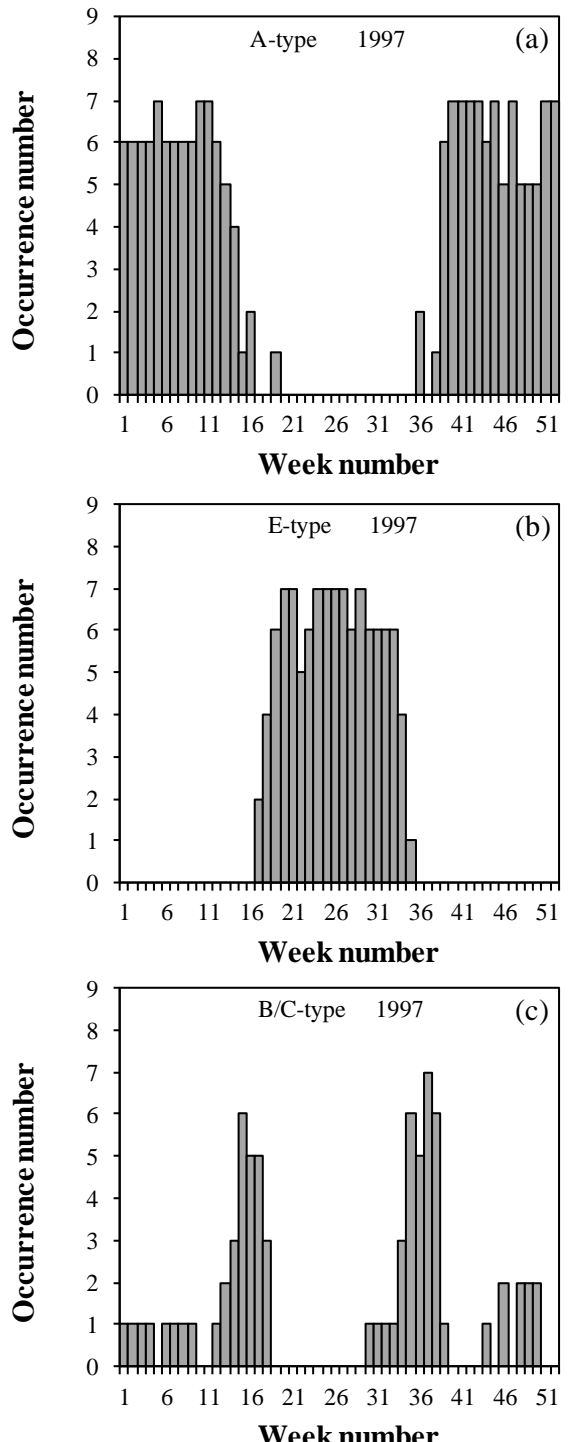

Week number

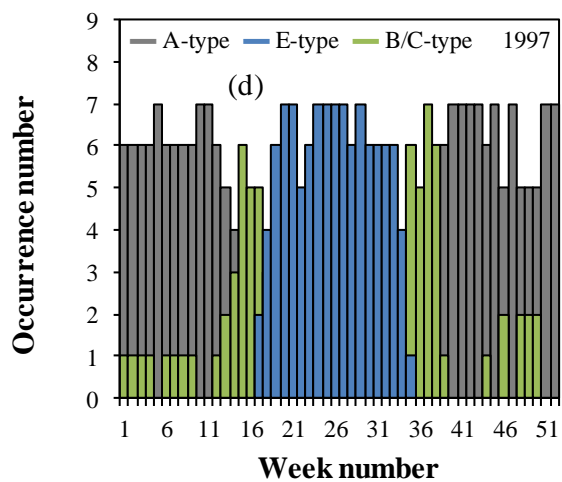

Figure 6. Same as Figs. 4 and 5 but for 1997, with clear seasonal behaviours of the F-layer patterns except with regard to the secondary season of the $\mathrm{B} / \mathrm{C}$ type during the period of January-February in (c).
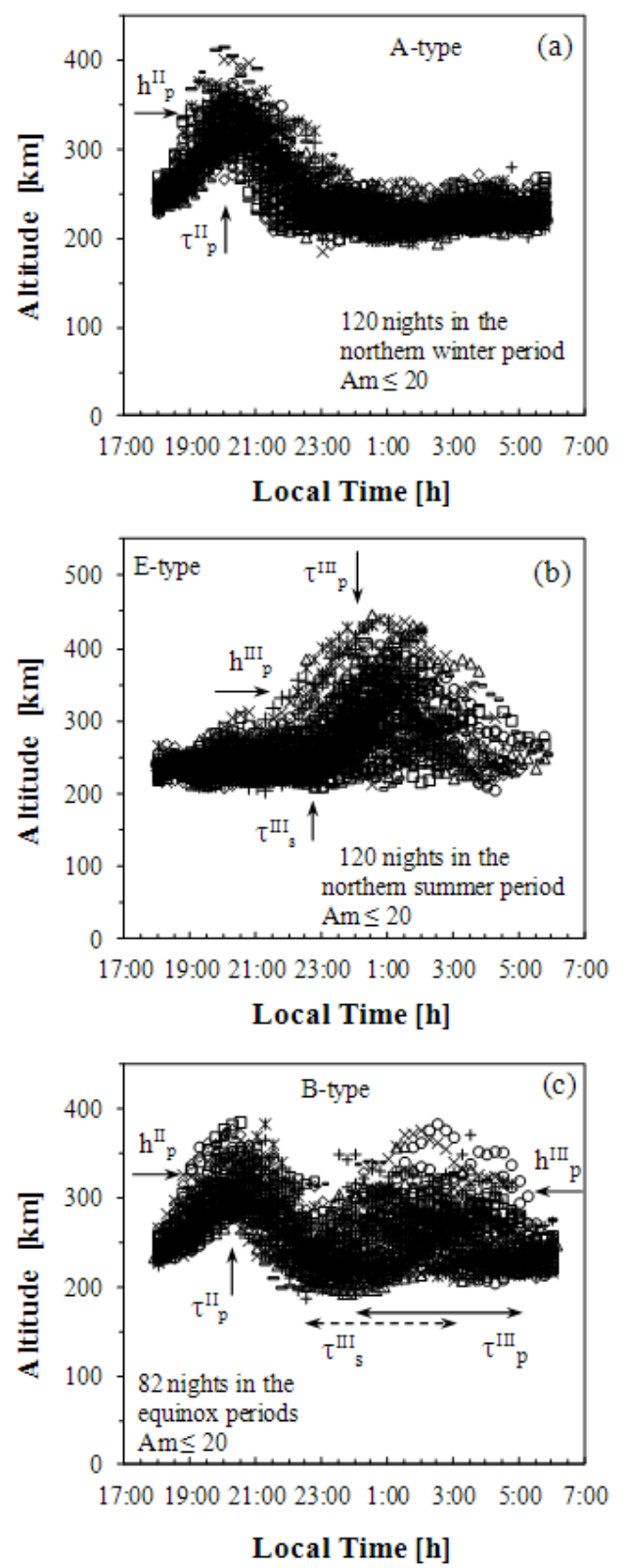

Figure 7. Night-to-night variability in the F-layer height as a function of LT over the solar minimum 1995-1997. Samples of 120 nights were used (a) during the periods from November to March and (b) during the periods from May to mid-August; a sample of 82 nights was used in (c) during the periods from the last week of March to the end of April and from mid-August to mid-September. The plot exhibits (a) A-type patterns, (b) E-type patterns and (c) B-type patterns. In (a) and (c), $h_{\mathrm{p}}^{\mathrm{II}}$ and $\tau_{\mathrm{p}}^{\mathrm{II}}$ denote the altitude and the time at the peak of phase II, respectively; in (b) and (c), $h_{\mathrm{p}}^{\mathrm{III}}$ and $\tau_{\mathrm{p}}^{\mathrm{III}}$ denote the altitude and the time at the peak of phase III, respectively, and $\tau_{\mathrm{s}}^{\mathrm{III}}$ the time at the start. Note in (c) that $\tau_{\mathrm{p}}^{\mathrm{III}}$ and $\tau_{\mathrm{S}}^{\mathrm{III}}$ vary in extended periods. 
Table 3. Distribution of the nights used for the statistical study of the A-, E- and B-type patterns over the whole solar minimum period 1995-1997.

Number of nights used for the statistic of the A-type pattern

\begin{tabular}{lrrr}
\hline & 1995 & 1996 & 1997 \\
\hline January & 9 & 10 & 9 \\
February & 8 & 9 & 5 \\
March & 11 & 5 & 7 \\
October & 13 & 3 & 7 \\
November & 9 & 7 & 5 \\
December & & 3 & \\
\hline
\end{tabular}

Number of nights used for the statistic of the E-type pattern

\begin{tabular}{lrrr}
\hline May & 18 & 20 & 10 \\
June & 13 & 13 & 11 \\
July & 14 & 3 & 7 \\
August & 11 & & \\
\hline
\end{tabular}

Number of nights used for the statistic of the B-type pattern

\begin{tabular}{lrrr}
\hline March & 1 & 3 & 2 \\
April & 17 & 12 & 14 \\
August & 8 & & 9 \\
September & 9 & & 7 \\
\hline
\end{tabular}

ters do not significantly fluctuate on the successive nights of the winter periods over these 3 years and (2) the mechanisms responsible for the motions associated with every phase of this type of pattern are reproducible. We find, for the evening uprising motion of phase II, apparent velocity values of about $18 \mathrm{~m} \mathrm{~s}^{-1}$ at the rise and $12 \mathrm{~m} \mathrm{~s}^{-1}$ during the descent. The peak altitude of about $340 \mathrm{~km}$ is reached at a characteristic time of 20:00 LT. We also find, for the bottom altitude in phase III, the characteristic value of about $225 \mathrm{~km}$. The evening uprising motion of phase II in the B-type pattern during the equinox periods (Fig. 7c) behaves similarly to that of the A type, for example with regard to the stable peak height at about $325 \mathrm{~km}$, the apparent drift velocity of about $16 \mathrm{~m} \mathrm{~s}^{-1}$ during the rise and $11 \mathrm{~m} \mathrm{~s}^{-1}$ during the descent, and the characteristic time of the peak at 20:00 LT. Thus, the evening layer elevation near the equinox periods is quite similar to that in the northern winter period. For more statistical studies, the altitude and characteristic time of the peak in phase II are labelled $h_{\mathrm{p}}^{\mathrm{II}}$ and $\tau_{\mathrm{p}}^{\mathrm{II}}$, respectively, and are indicated in Fig. $7 \mathrm{a}$ and $\mathrm{c}$.

Unlike the evening height peak in phase II, the amplitude and time of the height peak in phase III significantly scatter, as shown in Fig. 7b and c. In order to analyse this tendency, we compare the shapes of the motions for four successive nights during the 1995 northern summer period in Fig. 8. One observes that the peak shifts in time from one night

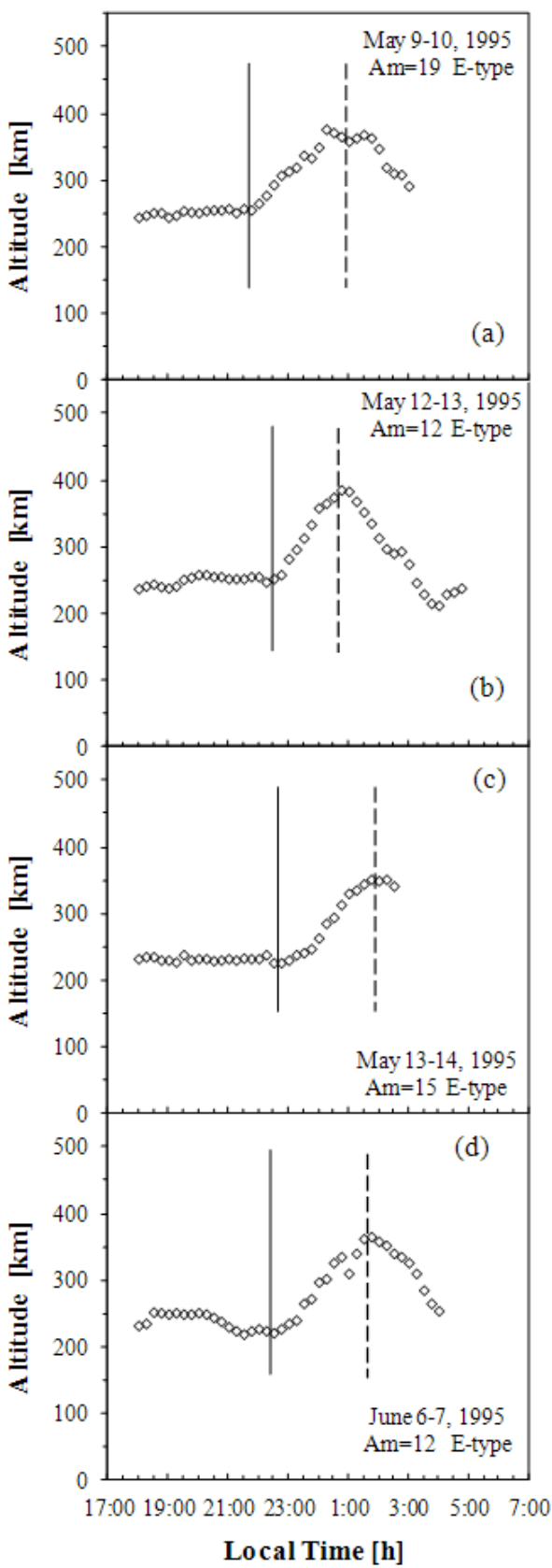

Figure 8. Night-to-night variability in the F-layer height as a function of LT for four nights with E-type patterns. The solid and dashed lines indicate the successive positions of the start and the maximum of the peaks, respectively, from one night to the next.

to the next, and its characteristic times at the start $\tau_{\mathrm{s}}^{\mathrm{III}}$ and at the maximum $\tau_{\mathrm{p}}^{\mathrm{III}}$, consequently, fluctuate, as indicated by the successive positions of the vertical solid and dashed lines, respectively. Similarly, the peak altitude $h_{\mathrm{p}}^{\mathrm{III}}$ fluctuates. Such features were also observed during the equinox periods. Therefore, we determined these parameters by statistical methods. 

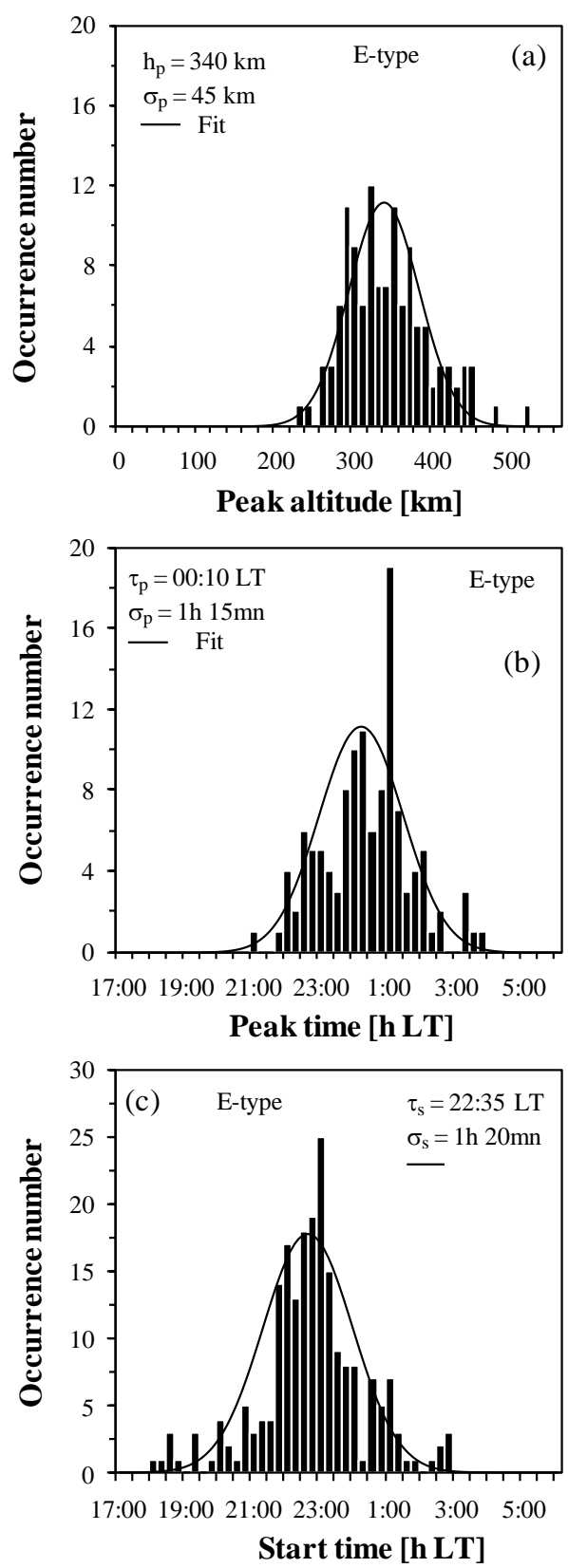

Figure 9. Statistical distributions of the characteristic parameters of the height peak of phase III in the northern summer period: (a) shows the altitude $h_{\mathrm{p}}^{\mathrm{III}}$ at the maximum, (b) the instant $\tau_{\mathrm{p}}^{\mathrm{III}}$ at the maximum and (c) the instant $\tau_{\mathrm{s}}^{\mathrm{III}}$ at the start. The solid line in each panel represents the fits of the data to the probability density function $p(x)=\frac{1}{\sigma \sqrt{ } 2 \pi} e^{-(x-m)^{2} / 2 \sigma^{2}}$, in which $x$ denotes the parameter $h_{\mathrm{p}}^{\mathrm{III}}, \tau_{\mathrm{p}}^{\mathrm{III}}$ or $\tau_{\mathrm{s}}^{\mathrm{III}}, m$ its most probable value, and $\sigma$ the corresponding dispersion parameter.

Figure $9 \mathrm{a}, \mathrm{b}$ and $\mathrm{c}$ show the histograms of the observations of $h_{\mathrm{p}}^{\mathrm{III}}, \tau_{\mathrm{p}}^{\mathrm{III}}$ and $\tau_{\mathrm{s}}^{\mathrm{III}}$, respectively, for the peak of the E-type pattern in Fig. 7b. Each of the distributions exhibits a maximum, indicating that despite the unstable behaviour of
Table 4. Characteristic parameters of the height peak of phase III in the E- and B-type patterns; $\tau_{\mathrm{S}}^{\mathrm{III}}$ denotes the instant at the start of the elevation and $\tau_{\mathrm{p}}^{\mathrm{III}}$ and $h_{\mathrm{p}}^{\mathrm{III}}$ denote the instant and altitude at the maximum. For each of these parameters, $m$ is the most probable value and $\sigma$ characterizes the dispersion. Note that, for the B-type pattern, $\tau_{\mathrm{s}}^{\mathrm{III}}$ and $\tau_{\mathrm{p}}^{\mathrm{III}}$ shift within extended time periods.

\begin{tabular}{llll}
\hline & $\tau_{\mathrm{s}}^{\mathrm{III}}$ & $\tau_{\mathrm{p}}^{\mathrm{III}}$ & $h_{\mathrm{p}}^{\mathrm{III}}$ \\
\hline \multicolumn{4}{c}{ E-type pattern } \\
\hline$m$ & $\begin{array}{l}22: 35 \mathrm{LT} \\
1 \mathrm{~h} 20 \mathrm{~min}\end{array}$ & $00: 10 \mathrm{LT}$ & $340 \mathrm{~km}$ \\
\multicolumn{4}{c}{ B-type pattern } \\
\hline$m$ & $22: 30 \mathrm{LT}$ & $00: 00 \mathrm{LT}$ & $45 \mathrm{~km}$ \\
\hline & - & - & $305 \mathrm{~km}$ \\
& $03: 00 \mathrm{LT}$ & $05: 00 \mathrm{LT}$ & $30 \mathrm{~km}$ \\
\hline
\end{tabular}

this peak, a pattern probably exists and can be used to characterize the summer period. Figure $9 \mathrm{a}-\mathrm{c}$ also show that the data are well fitted to the Gaussian law of probability density $p(x)=\frac{1}{\sigma \sqrt{ } 2 \pi} e^{-(x-m)^{2} / 2 \sigma^{2}}$, in which $x$ denotes the parameter $h_{\mathrm{p}}^{\mathrm{III}}, \tau_{\mathrm{p}}^{\mathrm{III}}$ or $\tau_{\mathrm{s}}^{\mathrm{III}}, m$ denotes its most probable value, and $\sigma$ is the corresponding dispersion parameter. Table 4 lists the values of $m$ and $\sigma$ for each of these parameters. We notice that in the northern summer period, most often, the layer uprising starts at $\tau_{\mathrm{s}}^{\mathrm{III}}=22: 35 \mathrm{LT}$ and the maximum altitude $h_{\mathrm{p}}^{\mathrm{III}}=340 \mathrm{~km}$ is reached at $\tau_{\mathrm{p}}^{\mathrm{III}}=00: 10 \mathrm{LT}$. Figure $10 \mathrm{a}, \mathrm{b}$ and c show the histograms of the observations of $h_{\mathrm{p}}^{\mathrm{III}}, \tau_{\mathrm{p}}^{\mathrm{III}}$ and $\tau_{\mathrm{s}}^{\mathrm{III}}$, respectively, for the peak of the B-type pattern in Fig. 7c. Figure 10a exhibits a narrow range of scatter and is well fitted to the Gaussian law of probability density. We find, for the peak altitude $h_{\mathrm{p}}^{\mathrm{III}}$, a value of about $305 \mathrm{~km}$, which is lower than that of about $340 \mathrm{~km}$ for the E-type pattern in Fig. $7 \mathrm{~b}$ and the value of about $30 \mathrm{~km}$ for the dispersion parameter $\sigma$. By contrast, in Fig. 10b, the distribution does not show a Gaussian behaviour. The instant of the peak varies rather randomly, within the extended period from about 00:00 to 05:00 LT, with up to $66 \%$ of the observations between 01:00 and 05:00 LT (Fig. 10b). Similar features are observed in Fig. 10c, and the start time is distributed randomly within the period from about 22:30 to 03:00 LT. These results indicate that, near the equinox periods, the F-layer elevation in phase III may arise at any time between 22:30 and 05:00 LT, the peak altitude reached in this case being lower than that in the northern summer period. The instant at the start of the elevation $\tau_{\mathrm{s}}^{\mathrm{III}}$ and the instant $\tau_{\mathrm{p}}^{\mathrm{III}}$ and altitude $h_{\mathrm{p}}^{\mathrm{III}}$ at the peak are indicated in Fig. $7 \mathrm{~b}$ and c. Table 4 lists their values. 


\section{Discussion}

In this section, we discuss our results based on earlier investigations of the equatorial F-region vertical plasma drifts. An important characteristic of the F-region vertical plasma drift is the prereversal enhancement of the upward velocity, which occurs during evening hours, due to an intensification of the eastward electric field (Rishbeth, 1971; Heelis et al., 1974). Several authors have shown that the prereversal velocity enhancement strongly depends on season, solar activity and longitude. Using incoherent scatter radar measurements at Jicamarca $\left(11.95^{\circ} \mathrm{S}, 76.87^{\circ} \mathrm{W} ; 2^{\circ} \mathrm{N}\right.$ dip lat), Peru, for the periods 1968-1988 and 1968-1992, Fejer et al. (1991) and Fejer and Scherliess (1999), respectively, showed that, in solar minimum conditions, the prereversal enhancement is more pronounced during the equinox periods (March-April and September-October) than during the northern winter period (November-February), with peak velocity values of $\sim 10$ and $\sim 5 \mathrm{~m} \mathrm{~s}^{-1}$, respectively, and is absent during the northern summer period (May-August). A similar seasonal dependence of the prereversal enhancement has been reported for Trivandrum $\left(8.51^{\circ} \mathrm{N}, 76.96^{\circ} \mathrm{E} ; 0.9^{\circ} \mathrm{S}\right.$ dip lat), India, for low-solar-activity conditions, from HF Doppler radar measurements for the year 1985 (Namboothiri et al., 1989). However, the peak velocity of $\sim 12 \mathrm{~m} \mathrm{~s}^{-1}$ is almost identical during the equinox and the northern winter periods and was observed to be higher than that during the winter period at Jicamarca. Scherliess and Fejer (1999) have combined incoherent scatter radar observations at Jicamarca from 1968 to 1992 and satellite observations from 1977 to 1979 to model the diurnal and seasonal variations in the equatorial vertical drifts for different longitude ranges and solar activity conditions. Both the model predictions and satellite data showed that during low-solar-activity periods the prereversal enhancement is (1) absent during the northern summer period (May-August) whatever the longitude sector, (2) more pronounced during the equinox periods (MarchApril and September-October) than during the northern winter period (November-February) in the African-Indian longitude sector $340-180^{\circ} \mathrm{E}$, with peak velocity values of $\sim 15$ and $\sim 5 \mathrm{~m} \mathrm{~s}^{-1}$, respectively, and (3) almost identical during the equinox and northern winter periods with a peak velocity value of $\sim 10 \mathrm{~m} \mathrm{~s}^{-1}$ in the American-Atlantic longitude sector $270-10^{\circ} \mathrm{E}$. We note that, mostly, the investigations on this subject have been carried out using techniques (incoherent scatter radar, HF radar, satellite, etc.) other than an ionosonde. Combined instruments, i.e. the Coupled Ion Neutral Dynamics Investigation (CINDI) instrument onboard the C/NOFS satellite, have also been used (Stoneback et al., 2011). It is clear that features found with such techniques may not be evident using a single ionosonde as in the current work. However, we can notice some similarities.

In our investigation of the night-time $h^{\prime} \mathrm{F}$ variations, two main patterns were clearly identified and referred to as the A type, characterized by an evening uplift during the north-
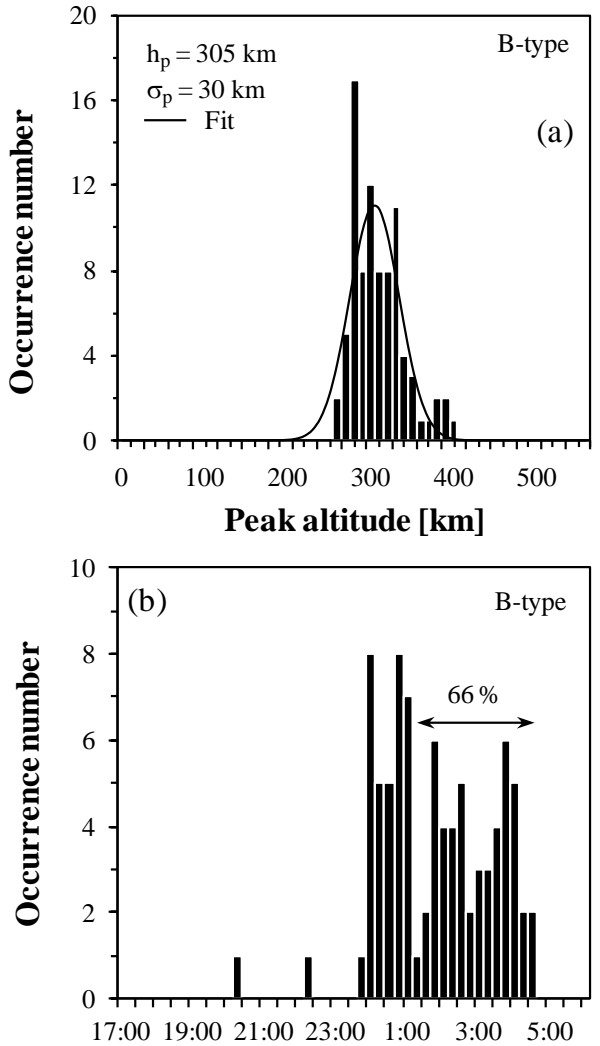

Peak time [h LT]

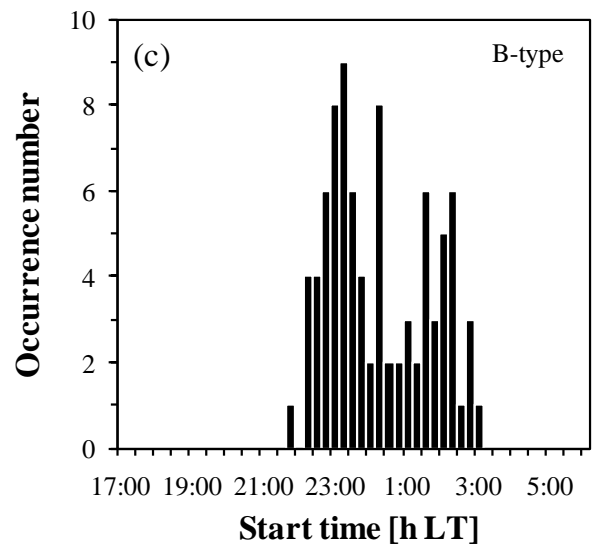

Figure 10. Same as Fig. 9 but for the equinox periods. Note that in (b) the instant at the maximum varies within the extended period from about 00:00 LT to 05:00 LT, indicating that, during the equinox periods, the uprising motion of phase III may reach its peak at any time in that period. Similarly, in (c) the instant at the start varies within the extended period from about 22:30 to 03:00 LT.

ern winter period, and the $\mathrm{E}$ type, characterized by a midnight uplift during the northern summer period. The transition from the A-type (E-type) to the E-type (A-type) patterns occurs in a few weeks around the equinox, during which both the uplifts are observed. Chandra and Rastogi (1972b) investigated the night-time variations in $h^{\prime} \mathrm{F}$ at equatorial stations 
during the International Geophysical Year and the International Geophysical Co-operation (IGY-IGC) period 19571959. Analysing the month-to-month patterns at Djibouti $\left(11.5^{\circ} \mathrm{N}, 43.0^{\circ} \mathrm{E} ; 6^{\circ} \mathrm{N}\right.$ dip lat), Djibouti and Kodaikanal $\left(10.2^{\circ} \mathrm{N}, 77.5^{\circ} \mathrm{E} ; 4^{\circ} \mathrm{N}\right.$ dip lat), India, they observed the presence of a sharp height peak at about 19:00 LT in DecemberJanuary that, progressively, becomes smooth and shifts to a later time around the midnight sector in June-July; it then, gradually, becomes sharp and shifts back to 19:00 LT by December. The authors attributed these changes to local seasonal effects or an asymmetry of the post-sunset height rise of the $\mathrm{F}$ layer over the magnetic equator during different seasons. Comparing these $h^{\prime} \mathrm{F}$ variations to those we observed in our experiments, we identify the pattern with the sharp peak in December-January as the A-type pattern and that with the smooth one in June-July as the E-type pattern. Therefore, the above seasonal changes in the $h^{\prime} \mathrm{F}$ patterns can be regarded as transition processes. However, the expected pattern with the sharp and smooth peaks together in the intermediate periods near April and September is not present in the $h^{\prime} \mathrm{F}$ plots by these authors. This is probably because the $h^{\prime} \mathrm{F}$ data were averaged monthly in the above work, a method that sometimes conceals (or suppresses) variable and relatively lowamplitude variations such as the peak of phase III during the equinox periods. We should state here that, although Chandra and Rastogi (1972b) observed this seasonal dependence of the $h^{\prime} \mathrm{F}$ variation, they did not clearly show the transition period from the winter (the summer) to the summer (the winter) patterns. To our knowledge, the current study is the first to show the transition state between the two solstices which exhibits the evening and midnight uplifts on the same nights.

We now consider the A-type pattern. One interesting feature in this pattern is the height peak at $\sim 20$ :00 LT, classically interpreted as the signature of the upward plasma drift associated with the prereversal enhancement of the eastward electric field near sunset (Fejer et al., 1979, 1989). In the current work, this peak showed seasonal variation, as it was observed to occur during the northern winter period and also at the equinox as part of the B-type pattern but with comparable amplitudes of $\sim 325-340 \mathrm{~km}$ (Fig. 7a and c) and comparable rise apparent drift velocities of $\sim 16-18 \mathrm{~m} \mathrm{~s}^{-1}$. These seasonal variations are consistent with the observations and model predictions (Scherliess and Fejer, 1999) that, at the solar minimum in the African-Indian longitude sector, evening enhancement of the upward drift velocity occurs during the winter months October-February and during the equinoxes. What contrasts with our results is the weaker $h^{\prime} \mathrm{F}$ amplitude in winter than at the equinox, expected from the above works in which the upward drift velocity was weaker at the solstice than the equinox $\sim 5$ and $\sim 15 \mathrm{~m} \mathrm{~s}^{-1}$, respectively. Such a difference was not observed in our experiments. The evening height peak instead exhibited similar behaviour at the equinox and in the northern winter period. When we compare our results to those of Namboothiri et al. (1989) for Trivandrum (a station also in the African-
Indian longitude sector), for the low-solar-activity condition, a good agreement is observed, as could be expected. As a matter of fact, these authors observed the presence of evening enhancement of the upward drift, with a comparable peak velocity of $\sim 12 \mathrm{~m} \mathrm{~s}^{-1}$ during the equinox and the northern winter periods, which is consistent with our observations of the $h^{\prime} \mathrm{F}$ variations. We should note here that both the current observations and those of Namboothiri et al. (1989) were conducted in the same longitude sector (African-Indian) and used ground-based techniques, namely an ionosonde and an HF Doppler radar, which may explain the above agreements. We have also compared our results to those of Scherliess and Fejer (1999) for the American-Atlantic longitude sector and solar minimum conditions. The observations and model predictions by these authors clearly indicated almost identical peak velocity of the evening upward drift of $\sim 10 \mathrm{~m} \mathrm{~s}^{-1}$ during the northern winter and equinox periods. This suggests at least comparable $h^{\prime} \mathrm{F}$ amplitudes and/or rise apparent drift velocities in winter and at the equinox, which is in qualitative agreement with our results $(\sim 325-340 \mathrm{~km}$ and $\sim 16-$ $18 \mathrm{~m} \mathrm{~s}^{-1}$ ). By contrast, when we compare our results to the model plots (Scherliess and Fejer, 1999) for the West African longitude sector (around $0^{\circ} \mathrm{E}$ ) and solar minimum conditions, we note that the evening enhancement of the upward drift occurs only during the equinox seasons (with a peak velocity of $\sim 20 \mathrm{~m} \mathrm{~s}^{-1}$ ), which contradicts with the seasonal variations in $h^{\prime} \mathrm{F}$ in the current work. The measurements by the C/NOFS satellite during the long solar minimum 20082010 in the longitude sector $300-360^{\circ}$ (Stoneback et al., 2011) also show agreements with our results, mainly because of the presence of the evening upward $\boldsymbol{E} \times \boldsymbol{B}$ drift pattern with an amplitude of $\sim 20 \mathrm{~m} \mathrm{~s}^{-1}$ during the northern winter period 2009-2010. During the spring equinox 2009, however, the evening upward drift was absent in the above work, in contrast with our results. The discrepancy between our results and those of Scherliess and Fejer (1999) for the African-Indian and the West African longitude sectors and of Stoneback et al. (2011) is possibly related to the measurement techniques. Firstly, the local time of satellite measurements at a given latitude shifts slowly due to the rotation of the orbital plane with respect to the Sun-Earth orientation and it takes a long time, depending on the orbital inclination angle, to sample data at all local times. Thus, seasonal and local time variations are not completely separated. Secondly, the parameters measured by satellites at the orbital height are in situ data and may differ from remote measurements (at $\sim 250 \mathrm{~km}$ ) by ground-based techniques, such as an ionosonde. Another possible source of discrepancy is the data processing. For example, Scherliess and Fejer (1999) divided the globe into four longitude sectors. In each sector, for a given season, the drift velocity was averaged in hourly LT bins over the whole period investigated (at least 2 years) and the plot of the drift velocity median value determined in this way as a function of LT was considered as representative of every station in the longitude sector. In such a method, (1) the 
$1 \mathrm{~h}$ LT bin is relatively large (as compared to the $15 \mathrm{~min}$ interval for data acquisition in the case of our ionosonde) and may not allow accounting for shorter-duration variations in the drift velocity, (2) longitudinal gradients in the drift velocity may be important and affect the data especially when the longitude ranges used are extended as is the case in the above works and (3) night-to-night and/or year-to-year variability of the drift velocity may be important. Thus, at a particular station, in a given night, the drift velocity can depart significantly from the median or average value.

We have also compared our results to those of Chandra and Rastogi (1972b). These authors investigated the nocturnal variations in $h^{\prime} \mathrm{F}$ at different stations near the equator from 1955 to 1964 . At Ibadan $\left(7.4^{\circ} \mathrm{N}, 3.9^{\circ} \mathrm{E} ; 6^{\circ} \mathrm{S}\right.$ dip lat) in the West African sector, for example, during the solar minimum period, $h^{\prime} \mathrm{F}$ clearly showed a post-sunset peak with a peak time of $\sim 19: 45 \mathrm{LT}$ and an altitude of $\sim 310 \mathrm{~km}$, almost identical with the evening height peak of phase II for the Aand B-type variations in the current results.

We now consider the E-type pattern. The three phases of this pattern show different features that would be interesting to analyse separately. Phase I of this pattern is characterized by a slow sunset uprising of the F layer, mostly associated with chemical recombination processes (Maruyama et al., 2002). In the current results, this phase is steadily observed over the year without noticeable seasonal variation. Phase II is characterized by a lack of post-sunset height peak, and the $h^{\prime} \mathrm{F}$ remains at a low height, at which $h^{\prime} \mathrm{F}$ is mostly controlled by the chemical recombination process, until $\sim 22: 35 \mathrm{LT}$. This $h^{\prime} \mathrm{F}$ variation is observed only during the northern summer period, as part of the E-type pattern. The lack of a postsunset height peak in the summer period is consistent with the lack of evening enhancement of the upward drift velocity during the northern summer periods in low-solar-activity conditions, as observations and model predictions (Scherliess and Fejer, 1999) for all longitude sectors showed. Our results also show good agreement with those of earlier investigations (Fejer et al., 1995) of the F-region vertical drifts carried out using the ion drift meter (IDM) measurements onboard the Atmosphere Explorer E (AE-E) satellite of the low-solar-activity year 1977. The diurnal variation in the longitudinally averaged vertical drift velocity, for magnetically quiet times, clearly showed the absence of evening enhancement during the period May-August. Vertical drift velocity investigations (Namboothiri et al., 1989) at Trivandrum, in the African-Indian longitude sector, also showed the absence of evening enhancement of the upward drift velocity during the northern summer and low-solar-activity periods, in agreement with the lack of a post-sunset height peak of phase II in the current results. We now consider phase III. This phase is characterized by the uplift near midnight, which strongly depends on the season and whose peak instant and altitude (in terms of $h^{\prime} \mathrm{F}$ variation) for a given season vary on successive nights. We observed that this uplift takes place (1) during the northern summer period at $\sim 00: 10 \mathrm{LT}$ with a peak alti- tude of $340 \pm 45 \mathrm{~km}$ and (2) during the equinox periods as part of the B-type pattern, within the extended interval from 22:30 LT to 05:00 LT and with a relatively lower peak altitude of $305 \pm 30 \mathrm{~km}$. These characteristics are different from those of the height peak in phase II of the A-type layer, suggesting that a different mechanism is involved. The F-region vertical drift model by Scherliess and Fejer (1999) cannot be used in the current analysis as it does not exhibit the midnight uplift. Nicolls et al. (2006) modelled post-midnight uplifts near the magnetic equator by combining numerical simulation methods and observations from two digital ionosondes at São José dos Campos $\left(23.2^{\circ} \mathrm{S}, 45.9^{\circ} \mathrm{W} ; 32^{\circ} \mathrm{S}\right.$ dip lat), Brazil, and Palmas $\left(10.2^{\circ} \mathrm{S}, 48.2^{\circ} \mathrm{W} ; 11^{\circ} \mathrm{S}\right.$ dip lat $)$, Brazil, and a digisonde at Jicamarca $\left(11.95^{\circ} \mathrm{S}, 76.87^{\circ} \mathrm{W} ; 1^{\circ} \mathrm{N}\right.$ dip lat), Peru, during the period 2002-2004. They showed that the post-midnight uplifts may occur without a reversal of the night-time westward electric field. The weakening of the westward electric field alone is sufficient to explain the uplifts if one takes account of the recombination effect at the bottom of the F layer. These authors invoked the midnight temperature maximum as a possible source of the weakening of the westward electric field. In their observations, the uplifts occurred in all seasons, between 01:00 and 05:00 LT, with almost identical monthly averages of the $h^{\prime} \mathrm{F}$ amplitude of $\sim 240-260 \mathrm{~km}$ at Palmas and Jicamarca. The seasonal dependence of the uplift of phase III in the current results is not evident in the investigations by Nicolls et al. (2006), possibly due to a longitude effect. By contrast, we note that the time interval in which the layer uprising of phase III is observed in our experiments during the equinox periods is extended until 05:00 LT, with up to $66 \%$ of the observations between 01:00 and 05:00 LT, which is consistent with the postmidnight uplift observations by these authors. We also note that the monthly average of the $h^{\prime} \mathrm{F}$ amplitude measured by these authors, $\sim 240-260 \mathrm{~km}$, is lower than the most probable value of $\sim 305 \mathrm{~km}$ of the peak altitude we found during the equinox periods. However, on the nights of 7-8, 9-10 and 14-15 October 2002, the $h^{\prime} \mathrm{F}$ amplitude of $\sim 275-340 \mathrm{~km}$ measured by these authors at Palmas is almost in the range of $275-335 \mathrm{~km}$, found in the current results during the equinox periods.

\section{Conclusions}

In this paper, we studied the night-time variations in the F-layer height in terms of $h^{\prime} \mathrm{F}$ at Korhogo $\left(9.2^{\circ} \mathrm{N}, 5^{\circ} \mathrm{W}\right.$; $2.4^{\circ} \mathrm{S}$ dip lat), Ivory Coast, in the West African sector, during the solar minimum period 1995-1997, by means of quarter-hourly data continuously collected from an IPS 42type ionosonde. The nocturnal variation pattern of $h^{\prime} \mathrm{F}$ as well as its night-to-night morphological changes were used to characterize the F-layer dynamics.

We showed that the night-time $\mathrm{F}$ layer undergoes three main vertical motions throughout the year, each associated 
with a specific mechanism. The first is the post sunset slow rise generally associated with rapid chemical recombination processes at the bottom of the $\mathrm{F}$ layer. It is followed either by the evening rise and fall motion classically associated with the prereversal enhancement of the eastward electric field and/or by a rise and fall motion around midnight, according to the season. The evening rise and fall motion occurs during the northern winter period October-March and is steadily observed throughout the solar minimum period. The peak altitude of the evening uplift is $\sim 340 \mathrm{~km}$ and is reached at $\sim 20$ :00 LT. The midnight rise and fall motion characterizes the northern summer period from May to mid-August. In that period, the layer starts rising at $\sim 22: 35 \mathrm{LT}$ and reaches its maximum altitude of $\sim 340 \mathrm{~km}$ at $\sim 00: 10 \mathrm{LT}$.

The transition from the regime with the evening rise and fall motion (resp. the midnight rise and fall motion) to that with the midnight one (resp. the evening one) occurs near the March (resp. the September) equinox period. It is progressive, lasts only 4-5 weeks and is characterized by the presence of both motions together with the post-sunset slow rise every night. During the transition periods, the evening rise and fall motion remains unchanged as compared to its pattern during the northern winter period, but the midnight uplift shifts in time between 00:00 and 05:00 LT, and its peak altitude is $\sim 305 \mathrm{~km}$ lower than during the northern summer.

We discussed these results in the light of earlier experimental and theoretical investigations of the F-region vertical drifts. The seasonal variability of the post-sunset rise and fall motion was compared to observations and/or model predictions for solar minimum conditions, for the African-Indian, American-Atlantic and West African longitude sectors, all including the longitude of Korhogo. A good agreement was observed with the observations and model predictions by Scherliess and Fejer (1999) for the American-Atlantic longitude sector. By contrast, the model predictions (by the same authors) that no evening enhancement of the upward drift occurs in November-February in the West African longitude sector and that the evening enhancement is stronger during the equinoxes than during the northern winter solstice period for the African-Indian longitude sector did not agree with our observations. The seasonal variability of the midnight uplift was also compared to other results, and particularly our observation that the midnight uplift shifts in time between 00:00 and 05:00 LT during the equinox transition periods was consistent with post-midnight observations at Palmas and Jicamarca by Nicolls et al. (2006).

This work shows evidence of the importance of West African data and will be pursued over a whole solar cycle, with the focus on analysing the effects of solar activity on F-layer height variations.

Author contributions. K. S. Tanoh processed the data from the ionograms of the 1992-1999 campaign for his thesis and designed the figures presented in this paper with the contribution of I. S.
Coulibaly, who is currently studying the influence of the storms on the ionospheric parameters using the data of the same campaign. B. J.-P. Adohi prepared the manuscript with the contribution of C. Amory-Mazaudier and K. S. Tanoh. C. Amory-Mazaudier arranged the paper with the contribution of A. T. Kobea and P. Assamoi.

Acknowledgements. K. S. Tanoh is grateful to the "Ministère de l'Enseignement Supérieur et de la Recherche Scientifique de Côted'Ivoire" for its financial support during his thesis period.

Topical Editor K. Hosokawa thanks H. Chandra and one anonymous referee for their help in evaluating this paper.

\section{References}

Adohi, B. J.-P., Vila, P. M., Amory-Mazaudier, C., and Petitdidier, M.: Equinox transition at the magnetic equator in Africa: analysis of ESF ionograms, Ann. Geophys., 26, 1777-1792, doi:10.5194/angeo-26-1777-2008, 2008.

Balan, N., Chen, C. Y., Rajesh, P. K., Liu, J. Y., and Bailey, G. J.: Modeling and observations of the low latitude ionosphereplasmasphere system at long deep solar minimum, J. Geophys. Res., 117, A08316, doi:10.1029/2012JA017846, 2012.

Batista, I. S., Abdu, M. A., and Bittencourt, J. A.: Equatorial F region vertical plasma drifts: Seasonal and longitudinal asymmetries in the American sector, J. Geophys. Res., 91, A11, 1205512064, 1986.

Chan, H. F. and Walker, G. O.: Computer simulation of the ionospheric equatorial anomaly in East Asia for equinoctial, solar minimum conditions. Part II. Results and discussion of wind effects, J. Atmos. Terr. Phys., 46, 1113-1120, 1984.

Chandra, H. and Rastogi, R. G.: Spread-F at magnetic equatorial station Thumba, Ann. Géophys., 28, 37-44, 1972a.

Chandra, H. and Rastogi, R. G.: Equatorial spread-F over a solar cycle, Ann. Géophys., 28, 709-716, 1972b.

Eccles, V. J.: Modeling investigation of the evening prereversal enhancement of the zonal electric field in the equatorial ionosphere, J. Geophys. Res., 103, 26709-26719, 1998.

Farges, T. and Vila, P. M.: Equatorial spread and dynamics in the F layer over West Africa from ionogram analysis, during the declining solar flux year 1994-1995, J. Atmos. Sol.-Terr. Phys., 65, 1309-1314, 2003.

Farley, D. T., Bonelli, E., Fejer, B. G., and Larsen, M. F.: The prereversal enhancement of the zonal electric field in the equatorial ionosphere, J. Geophys. Res., 91, 13723-13728, 1986.

Fejer, B. G., Farley, D. T., Woodman, R. F., and Calderon, C.: Dependence of equatorial $\mathrm{F}$ region vertical drifts on season and solar cycle, J. Geophys. Res., 84, 5792-5796, 1979.

Fejer, B. G., de Paula, E. R., Batista, I. S., Bonelli, E., and Woodman, R. F.: Equatorial F region vertical plasma drifts during solar maximum, J. Geophys. Res., 94, 12049-12054, 1989.

Fejer, B. G., de Paula, E. R., Gonzales, S. A., and Woodman, R. F.: Average vertical and zonal $F$ region plasma drifts over Jicamarca, J. Geophys. Res., 96, 13901-13906, 1991.

Fejer, B. G., de Paula, E. R., Heelis, R. A., and Hanson, W. B.: Global equatorial ionospheric vertical plasma drifts measured by the AE-E satellite, J. Geophys. Res., 100, 5769-5776, 1995. 
Fejer, B. G. and Scherliess, L.: Effects of the vertical plasma drift velocity on the generation and evolution of equatorial spread $\mathrm{F}$, J. Geophys. Res., 104, 19859-19869, 1999.

Heelis, R. A.: Electrodynamics in the low and middle latitude ionosphere: a tutorial, J. Atmos. Sol.-Terr. Phys., 66, 825-838, 2004.

Heelis, R. A., Kendall, P. C., Moffett, R. J., Windle, D. W., and Rishbeth, H.: Electrical coupling of the E- and F-regions and its effect on F-region drifts and winds, Planet. Space Sci., 22, 743756, 1974.

Krishna Murthy, B. V. and Subbarao, K. S. V.: Night-time equatorial F-region zonal plasma drifts from VHF backscatter radar observations, J. Atmos. Terr. Phys., 56, 529-534, 1994.

Kudeki, E. and Bhattacharyya, S.: Postsunset vortex in equatorial F-region plasma drifts and implications for bottomside spread-F, J. Geophys. Res., 104, 28163-28170, 1999.

Maruyama, T.: Modeling study of equatorial ionospheric height and spread F occurrence, J. Geophys. Res., 10, 5157-5163, 1996.

Maruyama, T., Nozaki, K., Yamamoto, M., and Fukao, S.: Ionospheric height changes at two closely separated equatorial stations and implications in spread $F$ onsets, J. Atmos. Sol.-Terr. Phys., 64, 1557-1563, 2002.

Menvielle, M. and Berthelier, A.: The K-derived planetary indices: Description and availability, Rev. Geophys., 29, 415-432, 1991.

Mueller-Wodarg, I.: The F2-Region, the Basics: Structure, Formation, School on the physics of equatorial atmosphere, The Abdus Salam International Centre for Theoretical Physics, 24 September-5 October 2001.

Namboothiri, S. P., Balan, N., and Rao, P. B.: Vertical plasma drifts in the $\mathrm{F}$ region at the magnetic equator, J. Geophys. Res., 94, 12055-12060, 1989.

Nicolls, M. J., Kelley, M. C., Vlasov, M. N., Sahai, Y., Chau, J. L., Hysell, D. L., Fagundes, P. R., Becker-Guedes, F., and Lima, W. L. C.: Observations and modeling of post-midnight uplifts near the magnetic equator, Ann. Geophys., 24, 1317-1331, doi:10.5194/angeo-24-1317-2006, 2006.
Pfaff, R., Rowland, D., Freudenreich, H., Bromund, K., Le, G., Acuña, M., Klenzing, J., Liebrecht, C., Martin, S., Burke, W. J., Maynard, N. C., Hunton, D. E., Roddy, P. A., Ballenthin, J. O., and Wilson, G. R.: Observations of DC electric fields in the lowlatitude ionosphere and their variations with local time, longitude, and plasma density during extreme solar minimum, J. Geophys. Res., 115, A12324, doi:10.1029/2010JA016023, 2010.

Rishbeth, H.: Polarization fields produced by winds in the equatorial F-region, Planet. Space Sci., 19, 357-369, 1971.

Saito, S. and Maruyama, T.: Ionospheric height variations observed by ionosondes along magnetic meridian and plasma bubble onsets, Ann. Geophys., 24, 2991-2996, doi:10.5194/angeo24-2991-2006, 2006.

Sastri, J. H., Abdu, M. A., Batista, I. S., and Sobral, J. H. A.: Onset conditions of equatorial (range) spread $\mathrm{F}$ at Fortaleza, Brazil, during the June solstice, J. Geophys. Res., 102, 24013-24021, 1997.

Sastri, J. H., Niranjan, K., and Subbarao, K. S. V.: Response of the equatorial ionosphere in the Indian (midnight) sector to the severe magnetic storm of July 15, 2000, Geophys. Res. Lett., 29, 13, doi:10.1029/2002GL015133, 2002.

Scherliess, L. and Fejer, B. G.: Radar and satellite global equatorial F region vertical drift model, J. Geophys. Res., 104, 6829-6842, 1999.

Stoneback, R. A., Heelis, R. A., Burrell, A. G., Coley, W. R., Fejer, B. G., and Pacheco, E.: Observations of quiet time vertical ion drift in the equatorial ionosphere during the solar minimum period of 2009, J. Geophys. Res., 116, A12327, doi:10.1029/2011JA016712, 2011.

Zerbo, J.-L., Amory-Mazaudier, C., and Ouattara, F.: Geomagnetism during solar cycle 23: Characteristics, J. Adv. Res., 4, 265-274, 2013. 